University of Nebraska - Lincoln

DigitalCommons@University of Nebraska - Lincoln

Faculty Publications from the Department of Electrical \& Computer Engineering, Department Electrical and Computer Engineering

2011

\title{
Wind/Solar Hybrid Generation-Based Roadway Microgrids
}

Wei Qiao

University of Nebraska-Lincoln, wqiao@engr.unl.edu

Anuj Sharma

University of Nebraska-Lincoln, asharma3@unl.edu

Jerry L. Hudgins

University of Nebraska-Lincoln, jhudgins2@unl.edu

Elizabeth G. Jones

University of Nebraska-Lincoln, libby.jones@unl.edu

Laurence Rilett

University of Nebraska-Lincoln, Irilett2@unl.edu

Follow this and additional works at: https://digitalcommons.unl.edu/electricalengineeringfacpub

Part of the Electrical and Computer Engineering Commons

Qiao, Wei; Sharma, Anuj; Hudgins, Jerry L.; Jones, Elizabeth G.; and Rilett, Laurence, "Wind/Solar Hybrid Generation-Based Roadway Microgrids" (2011). Faculty Publications from the Department of Electrical and Computer Engineering. 218.

https://digitalcommons.unl.edu/electricalengineeringfacpub/218

This Article is brought to you for free and open access by the Electrical \& Computer Engineering, Department of at DigitalCommons@University of Nebraska - Lincoln. It has been accepted for inclusion in Faculty Publications from the Department of Electrical and Computer Engineering by an authorized administrator of DigitalCommons@University of Nebraska - Lincoln. 


\title{
Wind/Solar Hybrid Generation-Based Roadway Microgrids
}

\author{
Wei Qiao, Member, IEEE, Anuj Sharma, Jerry L. Hudgins, Fellow, IEEE, Elizabeth G. Jones, and \\ Laurence Rilett
}

\begin{abstract}
This paper presents the concept and design of a novel roadway microgrid. It operates as a smart microgrid that optimally utilizes the public right-of-way and roadway infrastructure to provide cost-effective, highly efficient, and reliable wind/solar electric power production, distribution, storage, and utilization. The fundamental unit of the microgrid is called the energy-plus roadway/traffic signal light (EPRTL), which contains a grid-connected wind/solar hybrid generation system installed on the pole of a roadway/traffic signal light for clean electric power production. The term "energy-plus" stands for annual energy consumption that is less than production. The generated electric power will be consumed locally by the roadway/traffic signal light; the excess power generated will be stored in batteries, optimally distributed in the microgrid, and supplied to the utility main grid. The deployment of the proposed roadway microgrid will dramatically change the role of the public right-of-way from an energy consumer to an energy producer, leading to energy-plus roadways. This will not only reduce the roadway agency operating costs but also generate new revenues for the Highway Trust Fund. The use of renewable electric power will also promote the development of green roadways.
\end{abstract}

Index Terms-Battery, photovoltaic (PV) system, roadway microgrid, smart grid, wind turbine generator.

\section{INTRODUCTION}

$\mathrm{T}$ HE report of the National Surface Transportation Infrastructure Financing Commission [1] states that surface transportation has deteriorated to such an extent that our safety, economic competitiveness, and quality of life are at risk. The widening investment gap is identified as the root of the problem. Only one-third of the roughly $\$ 200$ billion necessary each year to maintain and improve the nation's highways and transit systems is raised as revenues by all levels of government. Renewable electric power production in the public right-of-way will cut the overall power needed to operate and maintain highway systems, and therefore, will reduce highway agency operating costs. The excess power

This material is based upon work supported by the Federal Highway Administration under Agreement No. DTFH61-10-H-00003. Any opinions, findings, and conclusions or recommendations expressed in this publication are those of the authors and do not necessarily reflect the view of the Federal Highway Administration.

W. Qiao and J. L. Hudgins are with the Department of Electrical Engineering, University of Nebraska-Lincoln, Lincoln, NE 68588-0511 USA (e-mail:wqiao@engr.unl.edu).

A. Sharma, E. Jones, and L. Rilett are with the Department of Civil Engineering, University of Nebraska-Lincoln, Lincoln, NE 68583-0855 USA. generated by renewable energy systems will generate revenues for the Highway Trust Fund.

In recent years, the use of photovoltaic (PV) technology for electric power generation and distribution has been accommodated within the highway right-of-way in several European countries [2]. In the United States, the first solar highway project was conducted by the Oregon Department of Transportation [3]. In that pilot project, a ground-mounted PV array was installed at the interchange of I-5 and I-205 and connected to the power grid for clean electricity generation and distribution.

This paper presents a novel concept and design of roadway micorgrid. The fundamental unit of the roadway microgrid is the energy-plus roadway/traffic-signal light (EPRTL), where energy-plus stands for annual energy consumption that is less than production. The EPRTL contains a grid-connected wind/solar hybrid generation system installed on the pole of a roadway/traffic signal light for electric power production. The generated electric power is consumed locally by the roadway/traffic signal light; the excess power generated by the EPRTL is stored in an optional battery system attached with the EPRTL or delivered through the roadway microgrid to supply other loads in the roadway microgrid or the utility main grid. The operation of each EPRTL and the overall roadway microgrid will be controlled by an optimal power management system. The resulting roadway microgrid will optimally utilize the public right-of-way and roadway infrastructure to provide cost-effective, highly efficient, and reliable wind/solar electric power production, distribution, storage, and utilization for both utility grid-connected mode and island mode.

The remaining sections of the paper are organized as follows. Section II introduces the concept, configuration, basic characteristics, and control of the roadway microgrid. Section III provides the detail on the design of the EPRTL. Section IV presents the preliminary implementation of an EPRTL as well as the economic and environmental benefits of deploying the roadway microgrid in the City of Lincoln, Nebraska. The last section summarizes the paper and provides further discussions on the roadway microgrid.

\section{The Proposed RoAdway Microgrid}

A roadway/traffic-signal arterial or roadway/traffic-signal network will provide an opportunity for a large number of EPRTLs to be in close proximity. The EPRTLs that are geographically close form a small power grid, which is called 


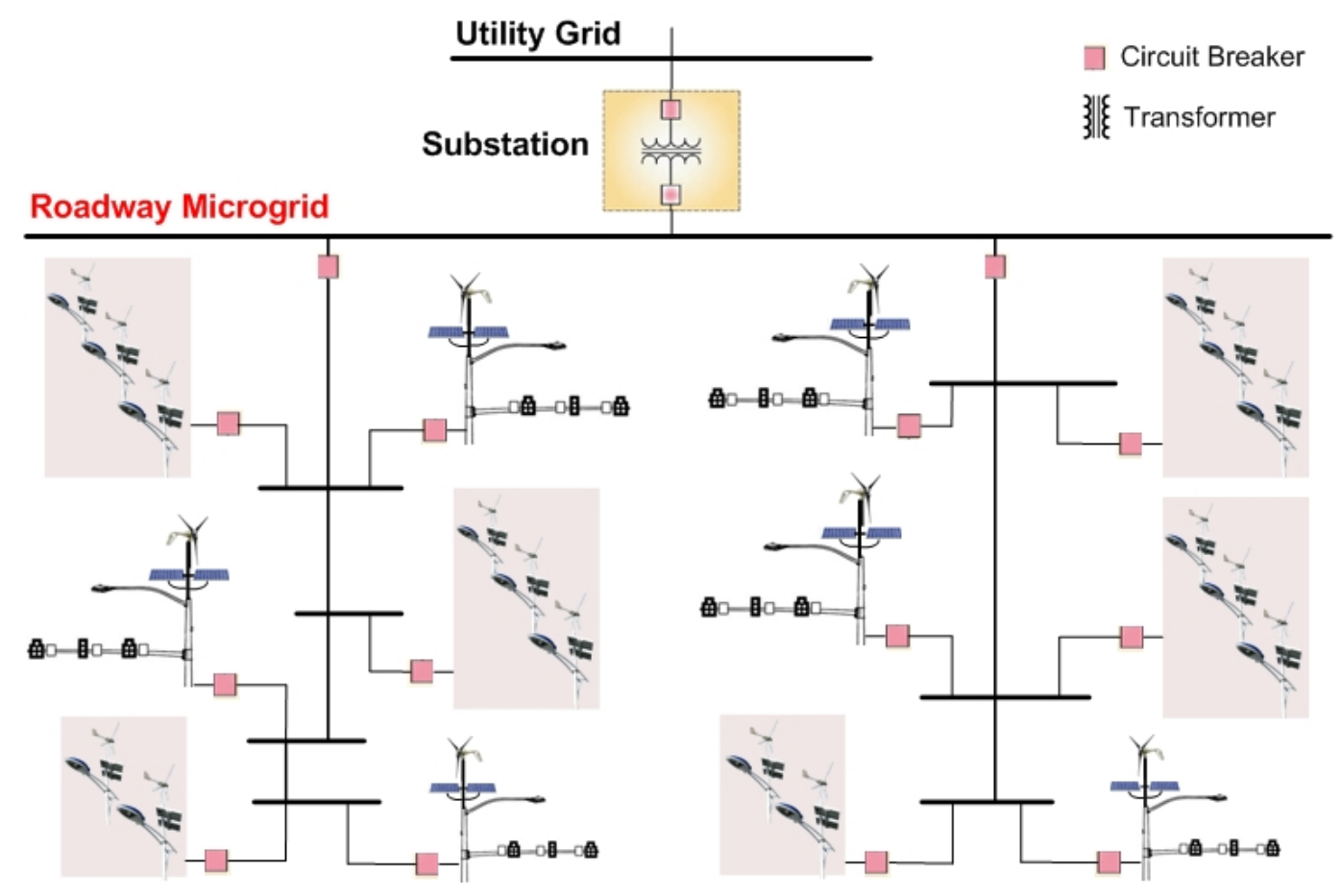

Fig. 1. The configuration of the roadway microgrid.

the roadway microgrid.

\section{A. Configuration of the Roadway Microgrid}

Fig. 1 illustrates a typical configuration for the roadway microgrid. The fundamental unit of the roadway microgrid is the EPRTL. Each EPRTL has a wind/solar hybrid generation system, consisting of a wind turbine generator and one or more PV panels mounted on the top of the pole for electric power generation. Each EPRTL, or a group of EPRTLs, e.g., all of the roadway lights within one block of a street, is connected to the existing power distribution grid through a circuit breaker. The EPRTLs that are geographically close form the roadway microgrid, which is connected to the utility main distribution grid at a small substation, consisting of a voltage step-up transformer and circuit breakers.

\section{B. Configuration of the EPRTL}

Fig. 2 illustrates a typical configuration for the EPRTL, which can be a traffic signal light, a street light, or both, as shown in the figure. The wind/solar hybrid generation system uses wind/solar resources to generate electric power, which is distributed through the roadway microgrid. A power electronics-based electric power conversion system is served as an interface between the EPRTL and the grid. This power electronics interface converts the electric power generated into the form required by the power grid and local load, such as the desired voltage level and frequency $(60 \mathrm{~Hz}$ in the United States). An optional energy storage system, e.g., a battery, could be used as a source or sink of the electric power to control the power exchanged between the EPRTL and the microgrid. The use of energy storage enables the roadway microgrid to operate in island mode to continuously supply high-quality electric power to the loads during contingencies of the utility main grid. The entire process of the electric power production, distribution, storage, and utilization of the EPRTL is controlled by a local power management controller (LPMC) and coordinated by a supervisory power management controller (SPMC) at the microgrid level, depending on the power management strategy adopted for the microgrid.

\section{Control of the Roadway Microgrid}

Many roadway traffic control systems have communication and networking infrastructure for closed-loop traffic signal operations. Such infrastructure can be utilized to develop a two-layer hierarchical power management system to control the electric power production, distribution, storage, and consumption within the roadway microgrid as well as the interactions between the microgrid and the utility main grid, as shown in Fig. 3. The SPMC is a central controller that

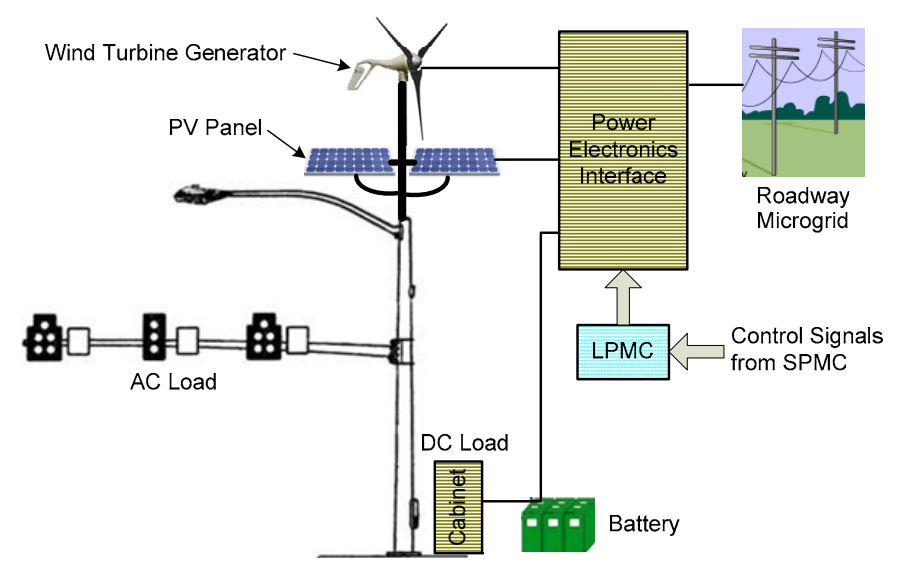

Fig. 2. The configuration of an EPRTL connected to the roadway microgrid. 
optimally coordinates the actions of all LPMCs by taking into account the regulations from the utility main grid. The overall power management system is developed to achieve the following objectives to make all EPRTLs the smart units and the entire roadway microgrid a smart microgrid.

Based on the demand and regulations from the utility main grid as well as the operating conditions of the microgrid, the central SPMC will determine the optimal set points of the low-layer LPMSs to achieve maximum economic benefits and performance optimization of the microgrid. The objectives to optimize control of the microgrid can include some of the following: voltage and frequency control, optimal generation scheduling, optimal power sharing among local EPRTL units and other loads in the microgrid, loss minimization of power distribution within the microgrid, demand-side management, emergency control, etc. In addition, the SPMC will provide a flexible control interface between the microgrid and the utility main grid and will be expandable for future integration of more EPRTL units. Furthermore, the SPMC will enable the microgrid to have a fast self-healing capability to reconfigure itself dynamically to recover from attacks, natural disasters, short circuits, or grid component failures.

The LPMC will provide a flexible control interface between each EPRTL unit and the microgrid. Based on the demand and regulations from the SPMC as well as the operating conditions of the EPRTL, each LPMC will determine the optimal control actions for the power electronic interface (see Fig. 3). The power electronic interface will then regulate power production, storage, and consumption of the EPRTL, such as optimal power sharing among the wind turbine generator, the PV panels and the energy storage system, maximum power point tracking (MPPT) control of the wind turbine generator and the PV panels, and emergency control.

An alternative to the centralized coordinating control strategy in Fig. 3 for power management of the microgrid is a multilayer distributed control architecture. A commonly used distributed control architecture is based on a multiagent system, as shown in Fig. 4. At the unit level, each agent represents an EPRTL unit; at the microgrid level, each agent

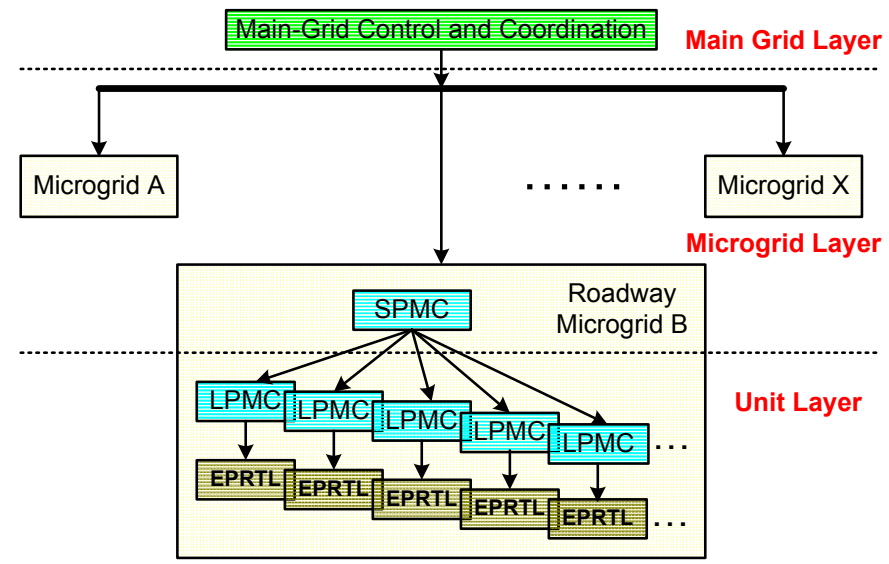

Fig. 3. A two-layer hierarchical power management system for the roadway microgrid. represents a roadway microgrid; at the main grid level, the agent represents the main grid. The agent is intelligent because it will be developed to have the functions of sensing, thinking (computing), decision, action, and communication. In a distributed control strategy, there are no global goals. The intelligent agents autonomously operate and cooperate with each other to meet their own objectives based on some predefined rules.

\section{Design Of The EPRTLS}

The EPRTL is the fundamental unit of the roadway microgrid. The topology of the EPRTL is designed based on the existing electrical infrastructure and load for traffic signals and street lights.

\section{A. Design the EPRTL for Traffic-Signal Systems}

Fig. 5 illustrates the typical configuration of four traffic poles at one intersection in the United States. The utility power grid supplies single-phase (1- $\Phi), 120-\mathrm{V}$ AC electric power to a cabinet, which distributes the $120-\mathrm{V}$ AC power to the four traffic poles through underground cables. Inside the cabinet, the $120-\mathrm{V}$ AC power is converted to $24-\mathrm{V}$ DC electric power for sensing, condition monitoring, control, etc. of the traffic signal system. An optional battery is connected to the 24-V DC bus to provide back up power during power outages.

Based on the configuration in Fig. 5, the configuration of the EPRTLs for the traffic-signal systems of one intersection is designed, as shown in Fig. 6. In each EPRTL, the wind

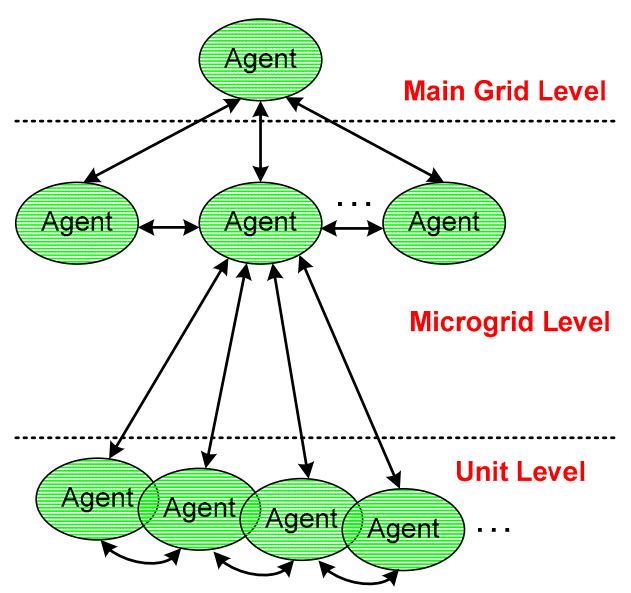

Fig. 4. Multilayer intelligent-agent-based distributed control strategy.

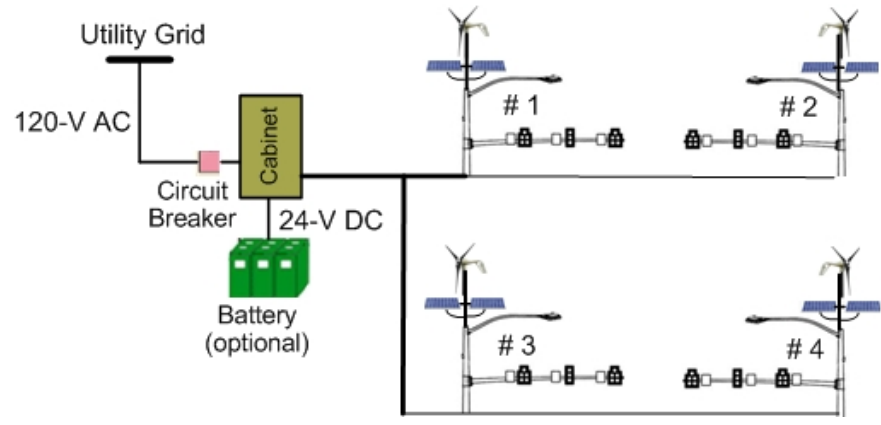

Fig. 5. Four traffic poles each with an EPRTL at an intersection. 


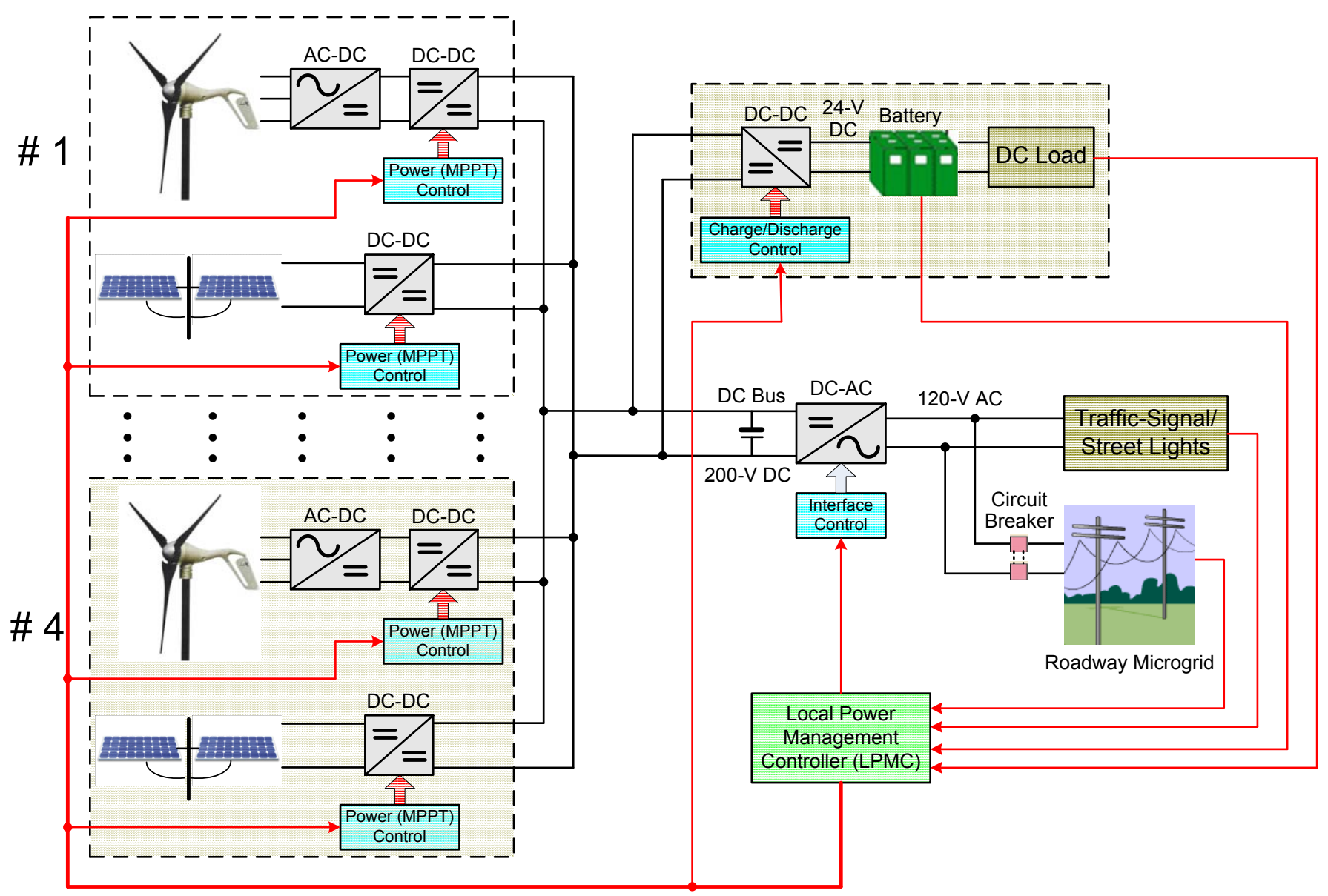

Fig. 6. The configuration of the EPRTLs for the traffic-signal system of one intersection.

turbine generator generates three-phase (3- $\Phi)$ AC electric power with variable voltages and frequency due to the variations in wind speed. A 3- $\Phi$ rectifier converts $A C$ power generated by the wind turbine generator to $\mathrm{DC}$ power. The voltage of this DC power is variable depending on the ACside voltage of the rectifier. The PV panels convert sunlight into unregulated DC electric power using the photoelectric effect. The variable DC power generated by the wind/solar hybrid system is collected to a constant-voltage DC bus, e.g., $200 \mathrm{~V}$, through dc-dc power electronic converters. A controller is developed for each dc-dc converter to control the corresponding wind turbine or PV panels to generate the desired amount of power. A typical control strategy is called the MPPT control, where the wind turbine and PV panels are always controlled to extract the maximum power from wind and sunlight, respectively. A 1- $\Phi \mathrm{dc}-\mathrm{ac}$ inverter then converts the DC power into $60-\mathrm{Hz}$ AC power and connects the wind/solar hybrid system to the roadway microgrid. If a battery is used, it is connected to the DC bus through a bidirectional dc-dc power electronic converter. This converter controls the charge and discharge of the battery. In this configuration, the battery serves as a source or sink of the electric power to control the power delivered to the roadway microgrid and local load from the wind/solar hybrid system. The controllers of the power electronic converters are coordinated by the LPMC.

\section{B. Sizing of the EPRTL Components}

Based on the wind and solar resources and the structural characteristics of the poles of traffic-signal and street lights, the power capacities of the wind turbines and PV panels are determined. For traffic poles, the power capacities of the wind turbines and PV panels are in the ranges of 500-3000 W and $100-400 \mathrm{~W}$, respectively. For the poles of street lights, the power capacities of the wind turbines and PV panels are in the range of $200-500 \mathrm{~W}$ and $80-200 \mathrm{~W}$, respectively. The size of the battery can be determined by the worst scenario when a power outage occurs in the utility main grid or in the microgrid while no power can be generated from the wind/solar hybrid systems, the traffic signal system should operate in required modes for required durations. For example, batteries used at some critical intersections in the City of Lincoln of Nebraska are required to supply power to allow the traffic signal system to operate in the normal mode for two hours and then in the flashing mode for another two hours. The traffic signal system at a typical intersection consumes $0.7 \mathrm{kWh}$ per hour in the normal mode and 0.35 $\mathrm{kWh}$ per hour in the flashing mode. Therefore, the capacity of the battery should be at least $2.1 \mathrm{kWh}$. However, with the availability of the wind/solar hybrid generation systems and the roadway microgrid, the size of the battery can be reduced. 


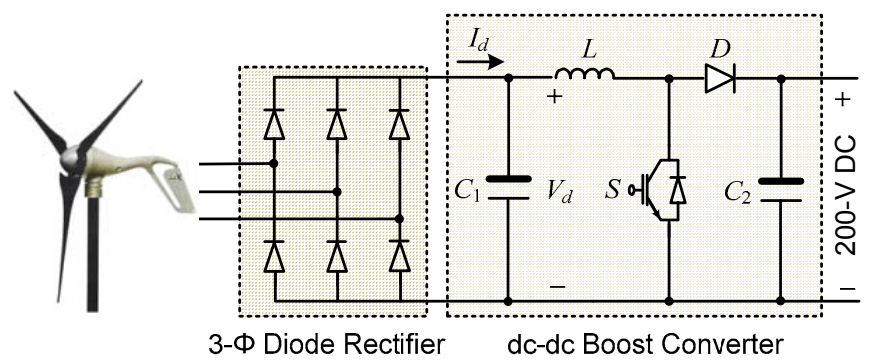

Fig. 7. The power electronic converters for the wind turbine generator.

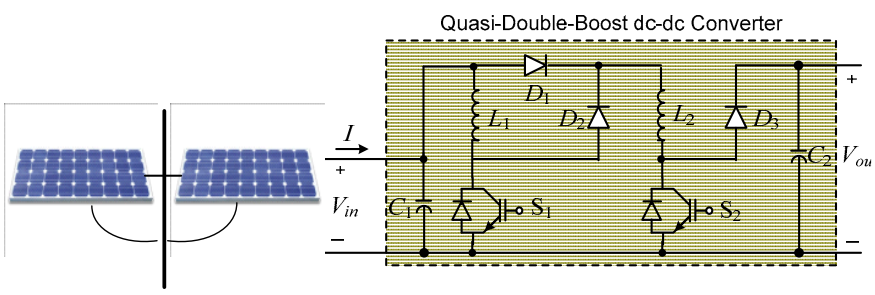

Fig. 8. The power electronic converter for the PV panels.

\section{Power Electronic Converters for the Wind Turbine Generator}

Fig. 7 shows the detailed topology of the power electronic converters for the wind turbine generator, where the ac-dc and dc-dc converters are implemented by a 3- $\Phi$ diode rectifier and a dc-dc boost converter [5], respectively. Due to the variations of wind sources, the magnitude and frequency of the output voltage of the wind turbine generator are variable. Consequently, the voltage at the DC terminal of the 3- $\Phi$ diode rectifier is variable, whose magnitude is lower than that of the DC-bus voltage required for the operation of the grid interface inverter. Therefore, a dc-dc boost converter is used to boost the DC-terminal voltage of the 3- $\Phi$ diode rectifier to a constant value at the required level.

\section{Power Electronic Converter for the PV Panels}

The power generated by the PV panels is fed to the common DC bus by a dc-dc converter. A characteristic of the PV system is that the voltage of the PV panels is relatively low (e.g., a few tens of volts) while the voltage of the common DC bus is relatively high (e.g., $200 \mathrm{~V})$. Therefore, a quasi-double-boost dc-dc converter [4], as shown in Fig. 8, is used. Compared to the standard dc-dc boost converter, the benefit of using the double-boost dc-dc converter is that at the same duty ratio and input voltage $V_{i n}$, the output voltage $V_{\text {out }}$ is doubled. Therefore, the converter can be operated close to its optimal duty ratio where the optimal efficiency can be achieved.

\section{E. Power Electronic Converter for the Battery}

Fig. 9 shows the topology of the dc-dc converter [5] for the battery, which can deliver power in two directions, i.e., from the battery to the $200-\mathrm{V}$ DC bus or reverse. The bidirectional dc-dc converter consists of an inductor $\left(L_{d c}\right)$ on the battery side and two half-bridge converters placed on each side of the main transformer $T_{r}$. A small capacitor $\left(C_{\mathrm{r} 1} \sim C_{\mathrm{r} 4}\right)$ across each

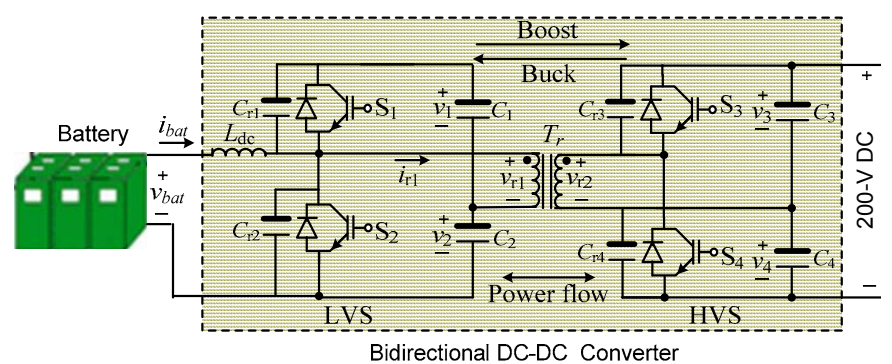

Fig. 9. The power electronic converter for the battery.

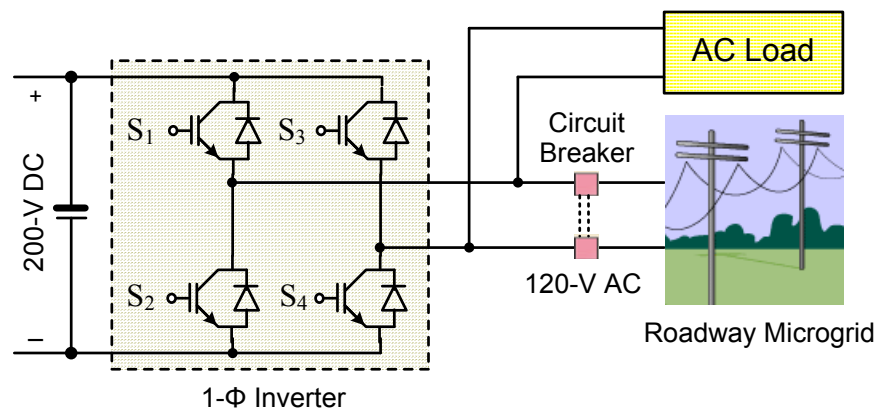

Fig. 10. The 1- $\Phi$ inverter for grid connection of the EPRTL.

of the four switches provides a lossless snubber for soft switching. The use of soft switching reduces the switching losses and stresses of the semiconductor switches of the circuit. The transformer is used to provide isolation and voltage matching between its two terminals. When power flows from the low-voltage battery side to the high-voltage (200-V) DC-bus side, the dc-dc converter works in the boost mode to boost the battery voltage (e.g., $24 \mathrm{~V})$ to a desired voltage level (200-V DC). In the other power flow direction, the dc-dc converter works in the buck mode to transfer power from the DC-bus side to the battery side to charge the battery. This bidirectional dc-dc converter has distinct advantages for applications that require high power density and low cost. The soft switching is achieved in either direction of the power flow without the need for any additional components.

\section{F. The Inverter for Grid Connection of the EPRTL}

The 1- $\Phi$ inverter is implemented by a full-bridge, pulsewise modulated (PWM) dc-ac inverter [6] for grid connection of the EPRTL, as shown in Fig. 10. The inverter serves as the interface between the wind/solar/battery units, the local AC load, and the roadway microgrid to control the active power exchanged among these elements. In principle, the net active power generated by the wind/solar generation units, consumed by the local load, supplied/stored by the battery, and delivered to or extracted from the microgrid should be zero at any times. This is achieved by controlling the DC-link voltage of the inverter to be constant. In addition to active power control, the inverter can also be arranged to supply/absorb the reactive power to/from the microgrid for voltage regulation of the microgrid. 

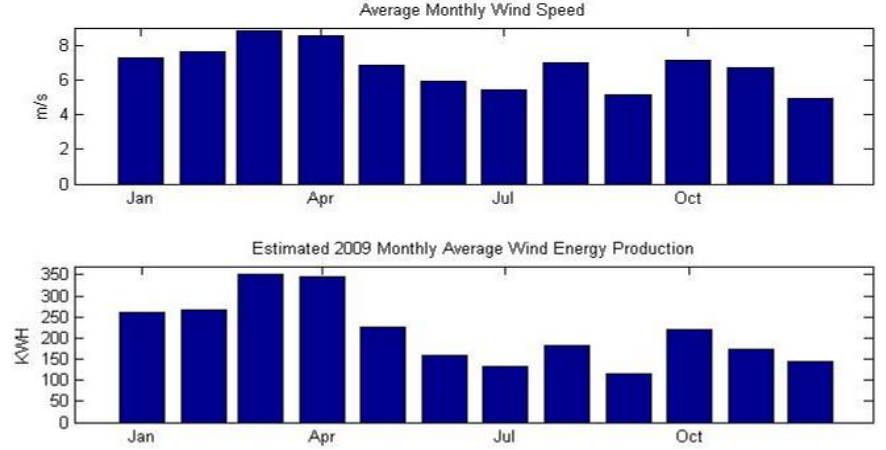

Fig. 11. Wind speed and estimated monthly energy production at $87^{\text {th }} \mathrm{St}$. and Highway 2 in 2009 in Lincoln, Nebraska.

\section{IMPLEMENTATION AND BENEFITS}

The proposed roadway microgrid will be developed in the Electric Power and Energy Systems Laboratory of the University of Nebraska-Lincoln and will be deployed in the City of Lincoln, Nebraska. Based on weather data and environmental conditions, an EPRTL test system consisting of a Bergey XL 1.0-kW wind turbine generator and lead-acid battery storage has been installed at the intersection of $84^{\text {th }}$ Street and Nebraska Highway 2 in the City of Lincoln. This is a suburban intersection and has no buildings nearby. The City of Lincoln Public Works Department, Lincoln Electric System, and University of Nebraska-Lincoln were collaboratively involved in the process of test system installation. A permanent Road Weather Information wind sensor is located at the intersection of $87^{\text {th }}$ Street and Highway 2 (3 blocks east of the test site). The estimated monthly average wind energy production in 2009 using the archived wind data from the wind sensor is shown in Fig. 11. The results show that one $1.0-\mathrm{kW}$ wind turbine generator is capable of generating more than 2,200 kWh of energy over the whole year. If a $1.0-\mathrm{kW}$ wind turbine generator is installed on each of the four traffic poles at the intersection, the total annul wind energy production will be more than 9,000 $\mathrm{kWh}$. This is much more than total annul energy consumption of approximately $6,000 \mathrm{kWh}$ of the traffic signal system at the intersection. Additional energy will be produced if PV panels are installed in the traffic signal poles.

It should be pointed out that there can be significant variation in wind generation among sites within a city. A rough estimate of energy production as well as economic and environmental benefits of deploying the proposed roadway microgrid has been done for the City of Lincoln. The City of Lincoln has 418 signalized intersections under its jurisdiction. The total electricity consumption is approximately 92,464 $\mathrm{kWh}$ per month. The analysis assumes that 200 intersections will be selected to install the EPRTL. Four EPRTL units can be mounted per intersection with one unit on each of the four traffic signal poles. Each EPRTL will consist of a $1.0-\mathrm{kW}$ wind turbine generator and 200-W PV panels. Based on historical wind and solar data, the total annul energy production from the city-wide roadway microgrid will be sufficient to meet the total electricity consumption of the traffic signal system in the City of Lincoln. The city-wide roadway microgrid over 15 years would have $\$ 1.5$ million in utility saving and reduce more than 12,000 tons of $\mathrm{CO}_{2}$ emission for the City of Lincoln. If the street light poles in the City of Lincoln are also used for deployment of the roadway microgrid, much more electricity can be generated, leading to energy-plus roadways.

\section{CONCLUSION AND Discussion}

This paper has presented the concept and design of a novel roadway microgrid. It optimally utilizes the public right-ofway and roadway infrastructure to provide cost-effective, highly efficient, and reliable wind/solar electric power production, distribution, storage, and utilization. The deployment of the roadway microgrid will dramatically change the role of the public right-of-way from an energy consumer to an energy producer, leading to energy-plus roadways. This will not only reduce the roadway agency operating costs but also generate new revenues for the Highway Trust Fund. The use of renewable electric power will also promote the development of green roadways.

Compared to current practice and approaches of using PV systems for electric power generation and distribution within the highway right-of-way, the proposed roadway microgrid has many novel and superior aspects and characteristics: 1) The roadway microgrid will have a lower footprint. 2) The roadway microgrid will be developed for urban and suburban areas which are load centers. The electric power generated will be used locally, and it will not require extra investments in power distribution systems. 3) The roadway microgrid will provide more continuous power generation because wind power and solar power supplement each other strongly. 4) The roadway microgrid will represent significant technology advances in multidisciplinary areas for the development of innovative renewable energy production and distribution systems. 5) The development and operation of the smart roadway microgrid will cover broader issues from energy production and distribution to grid operation and demand-side management. 6) The roadway microgrid will have no reflection problems, such as those associated with groundmounted PV systems, since the wind/solar hybrid generation system is mounted on the top of the pole of the roadway/traffic signal light. 7) The roadway microgrid does not require security fencing, continuous monitoring devices, or surveillance cameras to prevent theft and vandalism which are needed for ground-mounted PV systems. 8) The roadway microgrid can piggy back on existing maintenance resources for traffic signals.

\section{REFERENCES}

[1] "Paying our way: A new framework for transportation finance," Report of the National Surface Transportation Financing Commission, Feb. 26, 2009.

[2] V. Tsu, "Accommodation of renewable energy resources in the right-ofway," Department of Transportation. [Online]. Available: http:/www.fhwa.dot.gov/REALESTATE/newsletter/summer08.htm\#a3 
[3] The ODOT Solar Highway. [Online]. Available: http://www.oregon.gov/ODOT/HWY/OIPP/inn_solarhighway.shtml

[4] J. F. J. van Rensburg, M. J. Case, and D.V. Nicolae, "Double-boost dc to dc converter," in Proc. 34th Annual Conference of the IEEE Industrial Electronics Society, 2008, pp. 707-711.

[5] F. Z. Peng, H. Li, and G. J. Su, "A new ZVS bidirectional DC-DC converter for fuel cell and battery," IEEE Trans. Power Electronics, vol. 19, no. 1, pp. 54-65, Jan. 2004.

[6] Daniel W. Hart, Power Electronics, McGraw-Hill, 2010.

\section{BIOGRAPHIES}

Wei Qiao (S'05-M'08) received the B.Eng. and M.Eng. degrees in electrical engineering from Zhejiang University, Hangzhou, China, in 1997 and 2002, respectively, the M.S. degree in high performance computation for engineered systems from Singapore-MIT Alliance (SMA), Singapore, in 2003, and the $\mathrm{Ph} . \mathrm{D}$. degree in electrical engineering from Georgia Institute of Technology, Atlanta, in 2008 .

From 1997 to 1999, he was an Electrical Engineer with China Petroleum \& Chemical Corporation (Sinopec). Since 2008, he has been an Assistant Professor of Electrical Engineering with the University of Nebraska-Lincoln. His research interests include renewable energy systems, smart grids, power system control and optimization, condition monitoring and fault diagnosis, energy storage, power electronics, electric machines and drives, and computational intelligence for electric power and energy systems. He is the author or coauthor of 3 book chapters and more than 60 papers in refereed journals and international conference proceedings.

Dr. Qiao is an Associate Editor of the IEEE Transactions on Industry Applications, the Chair of the Sustainable Energy Sources Subcommittee of the IEEE Power Electronics Society, and the Chair of the Task Force on Intelligent Control for Wind Plants of the IEEE Power \& Energy Society. He was the Technical Program Cochair and Finance Cochair of the 2009 IEEE Symposium on Power Electronics and Machines in Wind Applications.

Dr. Qiao was the recipient of a 2010 NSF CAREER Award and the 2010 IEEE Industry Applications Society Andrew W. Smith Outstanding Young Member Award

Anuj Sharma received the B.E. degree from the National Institute of Technology, India in 2001, the M.S. degree from Texas A\&M University, College Station in 2004, and the Ph.D. degree from Purdue University, West Lafayette in 2008, all in civil engineering.

Since 2008, he has been an Assistant Professor of Civil Engineering with the University of Nebraska-Lincoln. His area of research is in Transportation Engineering. He is the coauthor of more than 20 papers in refereed journals and conference proceedings in his research area.

Jerry L. Hudgins (S'79-M'85-SM'91-F'04) received the Ph.D. degree in electrical engineering from Texas Tech University, Lubbock, in 1985.

He was with the faculty of University of South Carolina, Columbia, until 2004. He is presently with the University of Nebraska-Lincoln, where he is the Chair of the Electrical Engineering Department and also the Director of the Nebraska Wind Applications Center and Associate Director of the Nebraska Energy Sciences Research Center. He has published over 100 technical papers and book chapters concerning power semiconductors and engineering education, and has worked with numerous industries.

Dr. Hudgins was the President of the IEEE Power Electronics Society in 1997 and 1998 and the President of the IEEE Industry Applications Society in 2003. He has coauthored 3 award winning papers published by the IEEE Industry Applications Society and received the 1997 Best Transactions Paper Award for technical articles published in the IEEE Transactions on Power Electronics. He was the recipient of a 2000 IEEE Third Millennium Medal for "Outstanding Contributions in the area of Power Electronics."

Elizabeth G. Jones received the B.S. degree in civil engineering from the Colorado State University, in 1984 and the M.S. and Ph.D. degrees in civil engineering from The University of Texas at Austin in 1988 and 1996, respectively.

Currently, she is an Associate Professor of Civil Engineering with the University of Nebraska-Lincoln. Her area of research is in Intelligent Transportation Systems. She has authored or coauthored more than 20 refereed journal papers in her research area.
Laurence Rilett received the B.A.Sc. and M.A.Sc. degrees in Civil Engineering from the University of Waterloo and the Ph.D. degree in Civil Engineering from Queen's University, both in Canada.

Dr. Rilett is a Distinguished Professor of Civil Engineering at the University of Nebraska-Lincoln (UNL). He also serves as the Director of the UNL Mid-America Transportation Center and the Director of the Nebraska Transportation Center. His research interests include intelligent transportation systems applications and large-scale transportation system modeling. He has authored or co-authored more than 60 refereed journal papers and more than 70 conference papers.

Dr. Rilett is an Associate Editor of the ASCE Journal of Transportation Engineering and on the editorial board of the Journal of Intelligent Transportation Systems: Technology, Planning, and Operations. In 2002 he was awarded the Texas Transportation Institute TTI/Trinity Researcher Award and in 2007 he was awarded the UNL College of Engineering Research Award. 